\title{
Morphology and Anthropometry of Rhomboid Impression of Clavicle and its Clinical Applications - A South Indian Population Study
}

\author{
K.V. Sarala Devi ${ }^{\oplus 1}$, Sulochana Sakthivel ${ }^{\circledR 2}$ \\ ${ }^{1}$ Associate Professor, Department of Anatomy, ESIC Medical College \& Hospital, Gulbarga, Karnataka, India, ${ }^{2}$ Associate Professor, Department of Anatomy, Jawaharlal \\ Institute of Postgraduate Medical Education and Research, Gorimedu, Pondicherry, India.
}

\section{Abstract}

Introduction: The medial end of clavicle is connected to the upper surface of anterior end of first rib and its costal cartilage by rhomboid ligament which assist the movements of pectoral girdle as well as resist the pull of medial end of clavicle by pectoralis major and sternocleidomastiod muscles. Consequently, the attachment of it on the clavicle produces various patterns like tubercles, grooves, etc. called as the rhomboid impression. This normal variant of rhomboid impression may be interpreted sometimes as pathological lesions like necrosis, osteomyelitis, and tumour. Also, the morphology of rhomboid impression varies in different population. Such study in South Indian population is very much sparse and so this study is planned for. The objective is to it is aimed to estimate the prevalence of various morphology of rhomboid impression, to measure the anthropometry of impression and the distance from the medial end of impression to medial end of clavicle. Subjects and Methods: This descriptive study was carried in 200 adult human dry clavicles of both sides and various patterns of rhomboid impression, anteroposterior and transverse diameter of impression and distance between the medial end of impression and medial end of clavicle was measured with digital vernier caliper. Statistical analysis was done and p-value of $<0.05$ is considered to be significant. Results: The most common pattern observed was depression and rough (29\%) followed by elevated and rough (28.5\%). The resection length of the medial end of clavicle was $11 \mathrm{~mm}$ from the medial end of impression to medial end of clavicle. Conclusion: The findings of the present study on the morphology and anthropometry of rhomboid impression of adult human clavicles and the resection length of medial end of rhomboid impression from the medial end of clavicle will provide guidance for the anthropologists, orthopedicians, radiologists, vascular surgeons and in forensic investigations.

Keywords: Rhomboid impression, costoclavicular ligament, clavicular resection, South Indian.

Corresponding Author: Sulochana Sakthivel, Associate Professor, Department of Anatomy, Jawaharlal Institute of Postgraduate Medical Education and Research, Gorimedu, Pondicherry, India.

E-mail: sulo.ss@gmail.com

Received: 12 July 2020

Revised: 25 August 2020

Accepted: 31 August 2020

Published: 22 December 2020

\section{Introduction}

Costoclavicular ligament is an inverted conical ligament which is flattened anteroposteriorly and extends from the costal tuberosity on the inferior surface of medial end of clavicle to the first rib and its costal cartilage. It consists of anterior and posterior lamina separated by a bursa in-between. The ligament places an important role in the stabilisation of sternoclavicular joint and pectoral girdle. It resists the lateral pull by pectoralis major muscle and upward pull by the clavicular head of sternocleidomastiod muscle. Due to this fact, it is often prone for recurrent mechanical stress during extremes of such movements in certain occupationals like painters and construction workers. ${ }^{[1]}$

The costoclavicular ligament could produce landmarks at the site of its clavicular attachment. These impressions are called as the 'costal or rhomboid impression' which may exhibit various morphological patterns such as tubercle, rough impressionor a fossa. ${ }^{[2-5]}$ The impact of lifestyle and geography has also been documented for its existence. The knowledge of this is well utilised in forensic anthropology.

The subclavian vein is situated deep to coracoclavicular ligament and clinically, rhomboid impression provides guidance for the placement of venous catheters, pacemakers, and also in the resection of clavicle during sternoclavicular joint instability. ${ }^{[6-8]}$ Rhomboid impression is also utilised in anthropology as a marker for age and sex determination. ${ }^{\left[{ }^{[9}\right.}$ This normal variant of rhomboid impression may be interpreted occasionally for pathological lesions like necrosis, osteomyelitis, and tumour. ${ }^{[10]}$ Furthermore, it is misdiagnosed in its unilateral presentation on $\mathrm{X}$ rays. The morphological studies are very sparse with the maximum of 100 clavicles and no anthro- 
pometric studies have been conducted pertaining to the rhomboid impression in South Indian population. Henceforth our study is aimed to find out both the morphological as well as anthropometric aspects of rhomboid impression in 200 adult human clavicles of South Indian population.

\section{Subjects and Methods}

After obtaining approval from the institutional ethical committee, a descriptive study by observational method was carried out on 200 intact adult human dry clavicles of both sides (right - 83; left- 117) of both sexes. The bones were obtained from the department of Anatomy, ESIC Medical College and Hospital, Kalaburagi, Karnataka, India. The side of clavicle was identified with its standard features. ${ }^{[2]}$ The clavicles with incomplete features, old fractures, and previously operated were excluded from the study.

\section{Morphology:}

The various patterns of the impressions were observed by observation methodusing hand lens and were classified as follows: ${ }^{[10]}$

Type IA: Flat and rough

Type IB: Flat and smooth

Type IIA: Elevated and rough

Type IIB: Elevated and smooth

Type IIIA: Depressed and rough

Type IIIB: Depressed and smooth

\section{Anthropological measurement s:}

Using digital vernier caliper with an accuracy of $0.01 \mathrm{~mm}$, the anteroposterior diameter, transverse diameter and distance between the medial end of impression and medial end of the clavicle were measured in millimetre. The results were tabulated and the descriptive statistical analysis was carried out using SPSS version 19. Student ' $t$ ' test was applied to find the statistical difference between the right and left side and $p$-value $<0.05$ was considered statistically significant.

\section{Results}

Out of 200 clavicles, 195 (97.5\%) clavicles showed the impressions of various types and five clavicles $(2.5 \%)$ did not exhibit any impression [Table $1 \&$ Figure 1-3]. The elevated and depressed impressions were more commonly observed on the right clavicles whereas the flat impressions were more common on the left clavicles. The rough impressions were present in a greater number of clavicles when compared to the smooth ones. The right clavicles showed impressions of Types

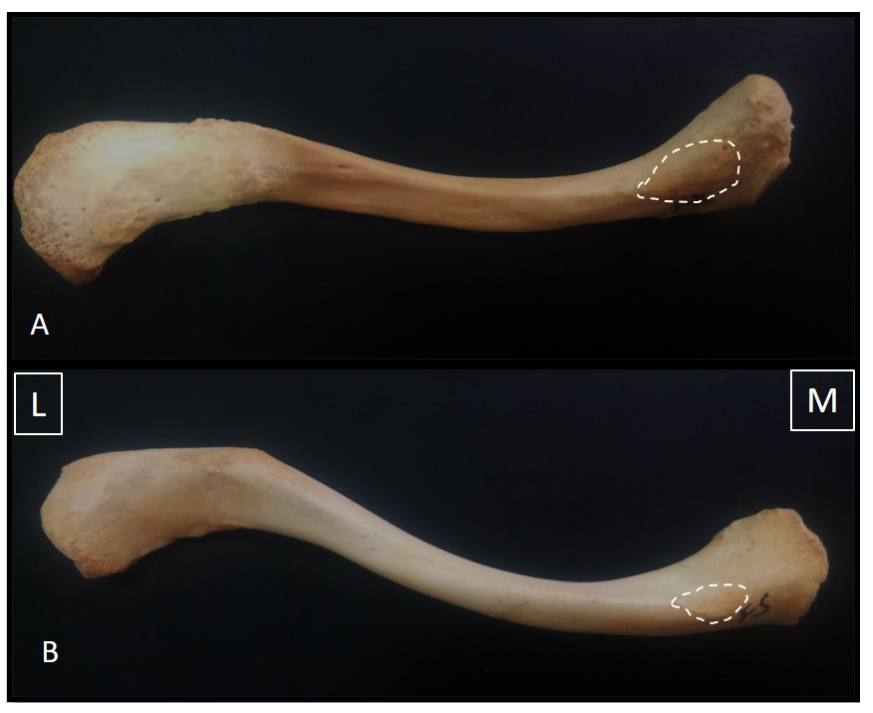

Figure 1: A) Type IA- Flat and rough impression. B) Type IB- Flat and smooth impression. (M- medial end; L- lateral end)

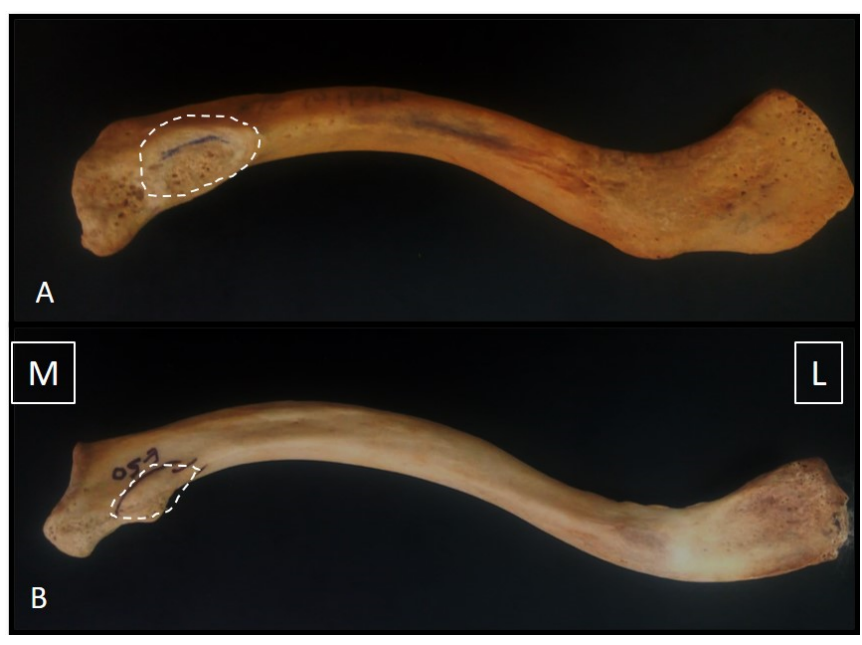

Figure 2: A) Type IIA- Elevated and rough impression. B) Type IIB- Elevated and smooth impression. (Mmedial end; L- lateral end)

IA, IIA, IIB, and IIIA whereas Types IA and IIIB were absent. The left clavicles revealed impressions of all types except Type IIB. Out of the 83 right clavicles, Type IIIA (depressed and rough) was found to be more frequent $(16 \%)$ and Type IIB (elevated and smooth) was less frequent (3.5\%). Out of the 117 left clavicles, Type IIA (elevated and rough) was observed more frequently (17.5\%) and Type IIIB (depressed and smooth) was less frequent (3\%) [Table 2]. 
Table 1: Distribution of patterns of impression on the clavicles $(n=200)$

\begin{tabular}{|llll|l}
\hline S. No & Side & Flat (Number \& percentage) & $\begin{array}{l}\text { Elevated (number \& } \\
\text { Percentage) }\end{array}$ & $\begin{array}{l}\text { Depressed } \\
\text { \& percentage) }\end{array}$ \\
\hline 1 & Right & $18(9 \%)$ & $29(14.5 \%)$ & $32(16 \%)$ \\
2 & Left & $52(26 \%)$ & $35(17.5 \%)$ & $29(14.5 \%)$ \\
3 & Total & $70(35 \%)$ & $64(32 \%)$ & $61(30.5 \%)$ \\
\hline
\end{tabular}

Table 2: Distribution of types of impression on the clavicles $(\mathrm{n}=\mathbf{2 0 0})$

\begin{tabular}{llllllll}
\hline S.no & Side & Type IA & Type IB & Type IIA & Type IIB & Type IIIA & Type IIIB \\
\hline 1 & Right & $18(9 \%)$ & 0 & $22(11 \%)$ & $7(3.5 \%)$ & $32(16 \%)$ & 0 \\
2 & Left & $22(11 \%)$ & $30(15 \%)$ & $35(17.5 \%)$ & 0 & $26(13 \%)$ & $3(1.5 \%)$ \\
3 & Total & $40(20 \%)$ & $30(15 \%)$ & $57(28.5 \%)$ & $7(3.5 \%)$ & $58(29 \%)$ & $3(1.5 \%)$ \\
\hline
\end{tabular}

(Type IA = Flat \& Rough; Type IB = Flat \& Smooth; Type IIA = Elevated \& Rough; Type IIB = Elevated \& Smooth; Type IIIA = Depressed \& Rough; Type IIIB $=$ Depressed \& Smooth)

Table 3: Anthropological measurement (in $\mathrm{mm})$ of impression on the clavicles $(\mathrm{n}=\mathbf{2 0 0})$

\begin{tabular}{lllll}
\hline S.no & Parameter & Minimum & Maximum & Mean \pm Std dev \\
1 & Anteroposterior diameter & 4 & 18 & $9.29 \pm 2.59$ \\
2 & Transverse diameter & 10 & 29 & $18.4 \pm 4.85$ \\
3 & $\begin{array}{l}\text { Distance from the medial } \\
\text { end of clavicle }\end{array}$ & 4 & 18 & $11.2 \pm 2.85$ \\
\hline
\end{tabular}

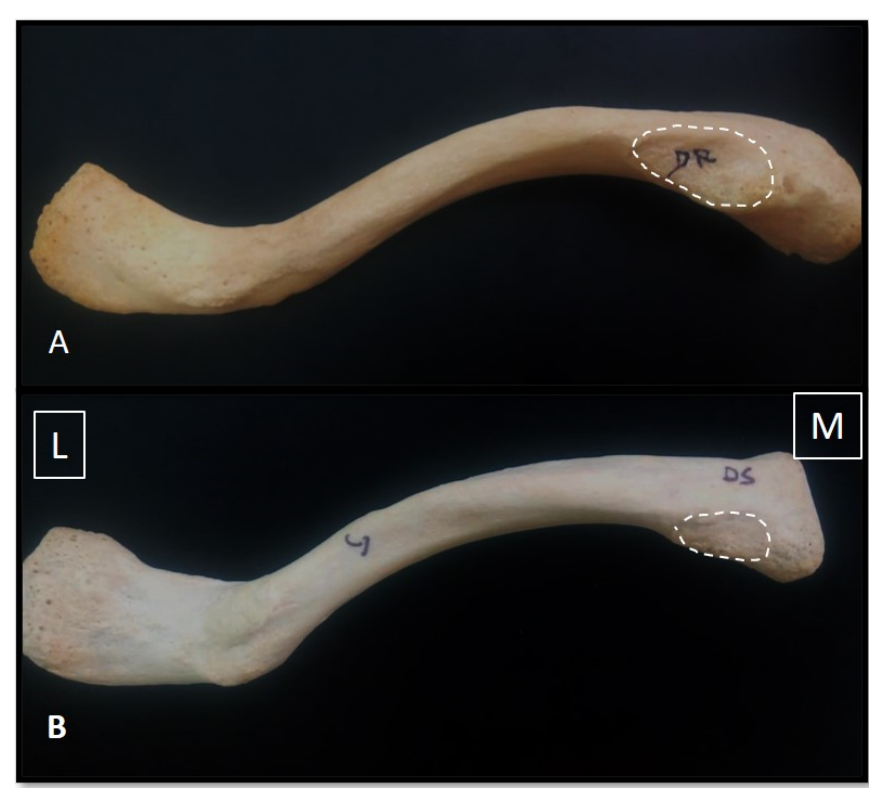

Figure 3: Type IIIA- Depressed and rough impression. B) Type IIIB- Depressed and smooth impression. (Mmedial end; L- lateral end)

The AP diameter range of 4-18 mm was statistically significant (p-value - 0.0005) whereas the transverse diameter range of 10-29mm was not statistically significant. Both the dimensions represented the shape of rhomboid impression in favour of oval shape. The mean distance between the medial margin of impression to the medial end of clavicle was $11 \mathrm{~mm} \pm 2.85 \mathrm{~mm}$ [Table 3].

\section{Discussion}

The area of attachment of costoclavicular ligament on the medial part of clavicle results in various morphological and anthropometric features. This may be correlated with functionality as it limits the sliding of the medial end of clavicle inferolaterally, during abduction. ${ }^{[11]}$ The tautness of the ligament has been noticed during the increase in abduction and internal rotation of the shoulder. ${ }^{[12]}$ This impression is documented in the determination of handedness as demonstrated well in the right clavicle in the righthanded person and in the left clavicle in the left-handed person. ${ }^{[13]}$ This normal variant is sometimes, due to the lack of its anatomical knowledge, misinterpreted as benign fibrous dysplasia or chronic osteomyelitis. ${ }^{[10]}$ The morphological variations were postulated secondary to the factors such as environmental, genetic, rate and pattern of growth as well as the type of bone remodelling. ${ }^{[14,15]}$ The roughness of impression is suggestive of the absence of intervening bursa with a subsequent direct attachment of the ligament to the clavicle. Nevertheless, the smoothness of impression 
correlated with the presence of bursa. ${ }^{[2]}$ The shape of the impression is most commonly described as oval-shaped and the size of the impression was measured to be more than 2 cm. ${ }^{[5,16]}$

Cave et al. demonstrated on 153 European adult clavicles that the flat and rough impression was the most common type $(31.3 \%)$ followed by the flat and smooth $(27.5 \%)$ which is contrary to our present study. ${ }^{[10]}$ In North-eastern Thais(476 clavicles), the authors observed no side differences and $76.26 \%$ of clavicles showed elevated impression which is higher than that of our present study. ${ }^{[17]}$ However, the smooth impression was found to be lower $(0.21 \%)$ as compared to our study $(20 \%) .{ }^{[17]}$

In a study on 60 clavicles in the region of Maharashtra of India, Type IA impression was observed more commonly in $63.33 \%$. ${ }^{[18]}$ Rani et al. studied 118 adult clavicles of the Indian population and concluded that the Type IIIA (depressed and rough) type impressions were more prevalent $(30.97 \%)$ and the Type IIIB (depressed and smooth) were least prevalent $(1.77 \%)$ which correlates with our study of $29 \%$ and $1.5 \%$ respectively. ${ }^{[19]}$

The results of the previous studies done in the South Indian population were in coincidence with our study regarding the incidence of Type IIIA [Table 4]. However, our study demonstrated Type IIIA as the most common presentation followed by Type IIA. The absence of impression has not been observed in other South Indian studies contrary to our study (2.5\%). Since the sample size (200 clavicles) of our study was comparatively higher than that of the other South Indian studies, our results may have more influence on the applied aspects of forensic anthropology and radiological interpretations.

The anthropometric measurements of the rhomboid impression have not yet been reported in the literature. The shape of the impressions was oval in outline in all the clavicles examined. The ranges of the anteroposterior diameter and the transverse diameter were 4-18 $\mathrm{mm}$ and $10-29 \mathrm{~mm}$ respectively. The anteroposterior diameter which was statistically significant as compared to transverse diameter might be helpful in anthropological investigations.

During surgical procedures such as sternoclavicular instability, the rhomboid ligament provides guidance for the resection of medial end of clavicle. ${ }^{[8]}$ To avoid the injury of rhomboid ligament, it is essential to measure the distance between the medial margin of impression and the medial end of clavicle. Vani et al. observed the resection length to be $8.33 \mathrm{~mm}(100$ clavicles) on the medial end of clavicle whereas our study (200 clavicles) demonstrated a resection length of $11 \mathrm{~mm}$ from the medial end of clavicle. ${ }^{[20]}$ Consequently, the resection length is important for a safer resection procedure as well as to define the exact position for subclavian vein catherisation.

\section{Conclusion}

The findings of the present study on the morphology and anthropometry of rhomboid impression of adult human clavicles and the resection length of medial end of rhomboid impression from the medial end of clavicle will provide guidance for the anthropologists, orthopedicians, radiologists, vascular surgeons and in forensic investigations.

\section{References}

1. Spencer EE, Kuhn JE, Huston LJ, Carpenter JE, Hughes RE. Ligamentous restraints to anterior and posterior translation of the sternoclavicular joint. J Shoulder Elbow Surg. 2002;11(1):43-47. Available from: https://dx.doi.org/10.1067/ mse.2002.119394.

2. Chahla J, Marchetti DC, Moatshe G, Ferrari MB, Sanchez G, Brady AW. Quantitative Assessment of the Coracoacromial and the Coracoclavicular Ligaments With 3-Dimensional Mapping of the Coracoid Process Anatomy: A Cadaveric Study of Surgically Relevant Structures. Arthroscopy. 2018;34(5):1403-1411. Available from: https:dx.doi.org/10. 1016/j.arthro.2017.11.033.

3. Grob K, Monahan RH, Manestar M, Filgueira L, Zdravkovic $\mathrm{V}$. The posterior ridge of the greater tuberosity of the humerus: a suitable landmark for the posterior approach to the shoulder joint? J Shoulder Elbow Surg. 2018;27(4):635-640. Available from: https://dx.doi.org/10.1016/j.jse.2017.10.034.

4. Moatshe G, Marchetti DC, Chahla J, Ferrari MB, Sanchez G, Lebus GF. Qualitative and Quantitative Anatomy of the Proximal Humerus Muscle Attachments and the Axillary Nerve: A Cadaveric Study. Arthroscopy . 2018;34(3):795803. Available from: https://dx.doi.org/10.1016/j.arthro.2017. 08.301 .

5. Shiu B, Jazini E, Robertson A, Henn RF, Hasan SA. Anatomical Relationship of the Axillary Nerve to the Pectoralis Major Tendon Insertion. Orthopedics . 2017;40(3):e460 e464. Available from: https://dx.doi.org/10.3928/0147744720170208-04.

6. Krutchen AE, Bjarnason H, Stackhouse DJ, Nazarian GK, Magney JE, Hunter DW. The mechanisms of positional dysfunction of subclavian venous catheters. Radiol. 1996;200(1):159163. Available from: https://dx.doi.org/10.1148/radiology.200. 1.8657904 .

7. Harada Y, Katsume A, Kimata M, Hikosaka T, Yamanaka $\mathrm{S}$, Akashi K, et al. Placement of pacemaker leads via the extrathoracic subclavian vein guided by fluoroscopy and venography in the oblique projection. Heart Vessels. 2005;20(1):19-22. Available from: https://dx.doi.org/10.1007/ s00380-004-0797-1.

8. Bisson LJ, Dauphin N, Marzo JM. A safe zone for resection of the medial end of the clavicle. J Shoulder Elbow Surg. 2003;12(6):592-594. Available from: https://dx.doi.org/10. 1016/s1058-2746(03)00176-9.

9. Prado FB, Santos LSDM, Caria PHF, Kawaguchi JT, d'O G Preza A, Jnr ED, et al. Incidence of clavicular rhomboid 


\begin{tabular}{|c|c|c|c|c|c|c|}
\hline S. no & Patterns & $\begin{array}{l}\text { Cave et } \\
\text { al.(1961). }\end{array}$ & $\begin{array}{l}\text { Rani et al. } \\
\text { (2011). }{ }^{[13]}\end{array}$ & $\begin{array}{l}\text { Vani et al. } \\
\text { (2018). }{ }^{[20]}\end{array}$ & $\begin{array}{l}\text { Rathnakar et } \\
\text { al. (2018). }\end{array}$ & $\begin{array}{l}\text { Present study } \\
(2020)\end{array}$ \\
\hline No of clavicles & - & 153 & 118 & 100 & 78 & 200 \\
\hline \multirow{2}{*}{$\begin{array}{l}\text { Population stud- } \\
\text { ied }\end{array}$} & - & Europeans & Indian & South Indians & South Indians & South Indians \\
\hline & Type IA & $31.3 \%$ & $28.32 \%$ & $26 \%$ & $6.4 \%$ & $20 \%$ \\
\hline 2 & Type IB & $27.5 \%$ & $6.19 \%$ & $16 \%$ & $6.4 \%$ & $15 \%$ \\
\hline 3 & Type IIA & $8.4 \%$ & $9.73 \%$ & $34 \%$ & $48.7 \%$ & $28.5 \%$ \\
\hline 4 & Type IIB & $2.6 \%$ & $19.47 \%$ & - & - & $3.5 \%$ \\
\hline 5 & Type IIIA & $17.6 \%$ & $30.97 \%$ & $24 \%$ & $29.5 \%$ & $29 \%$ \\
\hline 6 & Type IIIB & $10.4 \%$ & $1.77 \%$ & - & - & $1.5 \%$ \\
\hline 7 & $\begin{array}{l}\text { Absence of } \\
\text { impression }\end{array}$ & - & $3.54 \%$ & - & - & $2.5 \%$ \\
\hline
\end{tabular}

fossa (impression for costoclavicular ligament) in the Brazilian population: Forensic application. J forensic odontostomatol. 2009;27(1):12-16.

10. Cave AJE. The nature and morphology of the costoclavicular ligament. J Anat. 1961;95(2):170-179.

11. Dheer S, Zoga AC, Morrison WB. Clavicular avulsion of the costoclavicular (rhomboid) ligament: MRI findings. Radiol Case Rep. 2011;6(4):579. Available from: https://dx.doi.org/ 10.2484/rcr.v6i4.579.

12. Tubbs RS, Shah NA, Sullivan BP, Marchase MD, Cömert A, Acar HI, et al. The costoclavicular ligament revisited: a functional and anatomical study. Rom J Morphol Embryol. 2009;50(3):475-479.

13. Rani A, Chopra J, Rani A, Mishra SR, Srivastava AK, Sharma PK, et al. A study of morphological features of attachment area of costoclavicular ligament on clavicle and first rib in Indians and its clinical relevance. Biomed Res. 2011;22(3):349-354.

14. Humphrey LT, Dean MC, Stringer CB. Morphological variation in great ape and modern human mandibles. J Anat. 1999;195(4):491-513. Available from: https://dx.doi.org/10. 1046/j.1469-7580.1999.19540491.x.

15. Wood BA, Li Y, Willoughby C. Intraspecific variation and sexual dimorphism in cranial and dental variables among higher primates and their bearing on the homi-nid fossil record. J Anat. 1991;174:185-205.

16. Rathnakar P, K R, D C, Swathi S, Kumar V, Sinha A. Morphological Study of Attachment of Costoclavicular Ligament on the Clavicle in South Indian Population. J Evol Med Dent Sci. 2018;7(33):3684-3686. Available from: https://dx.doi.org/ 10.14260/jemds/2018/827.

17. Kaewma A, Sampannang A, Tuamsuk P, Kanpittaya J, Iamsaard S. Incidence of Clavicular Rhomboid Fossa in
Northeastern Thais: An Anthropological Study. Anat Res Int. 2016;2016:1-4. Available from: https://dx.doi.org/10.1155/ 2016/9298043.

18. Balvir T, Despande JV, Badwaik P, Rahule AS, Kasote A, Basheer M. Estimation of stature from the length of the clavicle in Vidarbha region of Maharashtra. Int J Biol med Res. 2015;3(4):2535-2537.

19. Rani A, Chopra J. A study of morphological features of attachment area ofcostoclavicular ligament on clavicle and first rib in Indians and its clinical relevance. Biomed Res. 2011;22(3):349-354.

20. Vani PC, Malsawmzuali JC, Anbalagan J, Rajasekar SS. Morphological study of clavicular rhomboid impression in South Indian population with its clinical significance. Int J Sci Res. 2018;7(2):30-32.

Copyright: (C) the author(s), 2020. It is an open-access article distributed under the terms of the Creative Commons Attribution License (CC BY 4.0), which permits authors to retain ownership of the copyright for their content, and allow anyone to download, reuse, reprint, modify, distribute and/or copy the content as long as the original authors and source are cited.

How to cite this article: Devi KVS, Sakthivel S. Morphology and Anthropometry of Rhomboid Impression of Clavicle and its Clinical Applications - A South Indian Population Study. Acad. Anat. Int. 2020;6(2):16-20.

DOI: dx.doi.org/10.21276/aanat.2020.6.2.3

Source of Support: Nil, Conflict of Interest: None declared. 